\title{
ENCONTRO DOS DIRETORES E DOS DOCENTES DAS ESCOLAS DE BIBLIOTECONOMIA DO MERCOSUL: UM RELATO DE MONITORIA
}

\author{
Jorge Santa Anna \\ Mestrando em Ciência da Informação PPGGOC - UFMG \\ jorjao20@yahoo.com.br
}

\section{Resumo}

\begin{abstract}
Os eventos científicos são considerados como importantes meios de comunicação científica, utilizados nas mais diferentes áreas do conhecimento. $\mathrm{Na}$ área de Biblioteconomia, um dos mais importantes eventos científicos direcionados à formação profissional é o Encontro dos Diretores e dos Docentes das Escolas de Biblioteconomia do Mercosul. Embora seja um evento de abrangência internacional e de suma contribuição para a Ciência da Informação, os objetivos e o sucesso do evento somente serão atingidos com a integração de diversas equipes de trabalho, sobretudo estudantes e profissionais que se encarregam nas atividades de monitoria. Portanto, este texto constitui um relato de experiência, a partir de monitoria realizada na XI edição do Encontro de Diretores e X edição do Encontro de Docentes. Objetiva, a partir das atividades realizadas ao longo do evento, apresentar as possíveis contribuições decorrentes da monitoria. Para isso, o texto apresenta discussões sobre práticas de organização de eventos elucidadas na literatura; descreve a definição e características dos principais tipos de eventos científicos, conforme teóricos da área; sintetiza as propostas didáticas presentes nos artigos apresentados; e, por fim, discorre sobre as principais contribuições do evento para a área e para o aprendizado do monitor. Utiliza pesquisa descritiva, com procedimentos de pesquisa bibliográfica e documental, além da observação participante. Os resultados indicaram que a atividade de monitoria agregou valor tanto para o evento quanto para o crescimento profissional do monitor, servindo como uma oportunidade para aquisição de novos conhecimentos relativos à área da Biblioteconomia, como também relacionados ao trabalho gerencial.
\end{abstract}

Palavras- chave: Eventos científicos. Práticas de organização de eventos. Escolas de Biblioteconomia do Mercosul. Formação profissional.

\section{INTRODUÇÃO}

A realização de eventos científicos constitui uma estratégia adotada pelas diversas áreas do conhecimento, com o intuito de tornar públicas as descobertas científicas que vêm sendo desenvolvidas por pesquisadores, como também, permitir que as inovações apresentadas possam ser apreciadas pelos participantes, de modo a agregar valor na melhoria das pesquisas em andamento, como propor recomendações para realização de novos estudos.

Trata-se, na verdade, de um momento de troca e socialização de conhecimentos, considerando as diferentes percepções e experiências vivenciadas por pesquisadores oriundos dos mais variados contextos e instâncias. $\mathrm{O}$ grande diferencial desse tipo de comunicação científica, segundo Campello (2003), reside no fato de que se manifesta o contato face a face entre os pesquisadores, o que proporciona um retorno imediato dos participantes aos estudos apresentados.

Considerando o propósito do evento, sua abrangência pode ser da mais diversificada, contemplando desde encontros locais, regionais, como abarcando extensões mais amplas, de cunho global, conforme descrito no estudo de Campello (2003). No caso dos eventos mais abrangentes, que envolvem instâncias internacionais, o momento torna-se ainda mais oportuno para troca de conhecimentos, sobretudo nos dias atuais, com a formação de blocos econômicos, os quais são instituídos, haja vista facilitar as relações econômicas, por conseguinte, eventos dessa 
natureza são considerados como promissores ao crescimento e valorização das profissões no mercado internacional.

Especificamente, no que se refere à área de Biblioteconomia, apresenta-se como um importante evento dessa natureza, o Encontro dos Diretores e Encontro de Docentes de Escolas de Biblioteconomia do MERCOSUL (EBCIM), o qual, na XI edição do Encontro de Diretores e X edição do Encontro de Docentes, tem viabilizado contribuições valiosas para o fortalecimento dessa área no âmbito desse bloco econômico.

No ano de 2016, este evento foi realizado na Escola de Ciência da Informação da Universidade Federal de Minas Gerais (ECI/UFMG), entre os dias 18 a 20 de setembro, contemplado pelo seguinte tema: "A Biblioteconomia em diálogo com a Arquivologia e a Museologia: desafios e interlocuções em equipamentos culturais".

Sendo assim, este texto compõe um relato de experiência, tendo em vista a participação do autor, como monitor durante a realização do EBCIM/2016. Objetiva, a partir das atividades realizadas ao longo do evento, apresentar as possíveis contribuições decorrentes da monitoria. Para tanto, são estabelecidos como objetivos específicos: apresentar discussões sobre as práticas de organização de eventos elucidadas na literatura; descrever as definições e características dos principais tipos de eventos científicos, conforme teóricos da área; sintetizar as propostas didáticas apresentadas nos artigos do EBCIM/2016; discorrer sobre as principais contribuições do evento para a área e para o aprendizado do monitor.

Metodologicamente, recorreu-se à pesquisa descritiva, com procedimentos de pesquisa bibliográfica e documental, além da observação participante. Para a pesquisa bibliográfica, utilizaram-se artigos e livros da área de comunicação científica, enquanto que na documental, procedeu-se a consultas aos Anais Eletrônicos do evento. Por sua vez, a observação participante se manifestou durante os três dias do evento, em práticas de monitoria realizadas pelo pesquisador.

\section{MARCO TEÓRICO DE REFERÊNCIA PARA O RELATO}

Uma das atividades que permeiam $o$ universo científico diz respeito à comunicação científica. Isso porque, a ciência fundamentase na produção de conhecimento, a qual está em constante desenvolvimento; portanto, é a partir de determinadas descobertas que se sustentam indagações, de modo a refutar, ampliar, confirmar e/ou aperfeiçoar o que até então era considerado como novo entre especialistas de uma dada área do conhecimento.

Assim, o processo de produção de conhecimento manifesta-se de forma processual, contemplando um conjunto de etapas iniciadas com as primeiras ideias formuladas por um cientista, perpassando a fase de experimentos, até o momento que se obtêm os resultados, sejam eles parciais quanto finais, os quais devem ser disponibilizados para apreciação da comunidade científica.

No decurso desse processo dinâmico, consolidam-se práticas comunicativas, em que as ideias sustentadas em um processo de pesquisa vão sendo apreciadas/avaliadas, de modo a garantir consistência, integridade e legitimidade. Portanto, conforme descrito por Mueller (2003), a comunicação científica é condição fundamental para o desenvolvimento da ciência, sendo que ela caracteriza-se pela intensa disseminação de informações especializadas divulgadas entre os pares. A interação que perfaz essas práticas visa, segundo Bueno (2010, p. 1), “[...] tornar conhecidos, na comunidade científica, os avanços obtidos (resultados de pesquisas, relatos de experiências, etc.) em áreas específicas ou a elaboração de novas teorias ou refinamento das existentes [...]".

Observa-se que ciência e comunicação estão intimamente relacionadas, sendo a comunicação necessária para explicitar o conhecimento produzido, tornando-o público, ou melhor, aprovado e publicado. Medeiros (2009) afirma que toda pesquisa de aspecto científico deve ser comunicada. A partir daí, segundo Campello (2003), percebe-se a preocupação das diversas áreas do conhecimento em valorizar o processo comunicativo, seja por meio da manutenção de periódicos como a elaboração de eventos científicos, permitindo que as pesquisas sejam compartilhadas e as áreas tornem-se legitimadas na sociedade.

Seja qual for o tipo de comunicação utilizado pelas áreas do conhecimento, é importante considerar que o pesquisador deve desenvolver estratégias que permitam a 
compreensão das mensagens pelos receptores. Nesse contexto, comunicar significa transmitir informações e viabilizar a compreensão, com o uso de símbolos comuns (verbais e não verbais). Tal processo "[...] não significa apenas enviar uma informação ou mensagem, mas torná-la comum entre as pessoas envolvidas" (SENARC, 2009, p. 4).

A comunicação se manifesta por meio do uso de diversos canais, podendo esses serem classificados como formais quanto informais. Para Meadows (1999), os canais informais são utilizados no iniciar das pesquisas, correspondendo ao primeiro contato entre os pesquisadores, enquanto que os canais formais abrangem um processo avaliativo mais rigoroso e contemplam um número maior de pessoas, momento em que os resultados da pesquisa são amplamente divulgados.

Importante mencionar que, com o desenvolvimento das tecnologias, os canais comunicativos vêm permitindo novas formas de interação entre pesquisadores. Segundo Mueller (2003), no passado, durante muito tempo, a comunicação era restrita ao uso de cartas manuscritas entre os especialistas, o que demandava muito tempo para avaliação e aprovação dos estudos. $\mathrm{Na}$ atualidade, a internet permitiu o surgimento de novas formas de contato entre pesquisadores, popularizando o uso dos canais informais, tais como blogs, listas de discussão, e-mails, dentre muitas outras possibilidades.

Não resta dúvida de que, um dos meios de comunicação mais utilizado no universo científico diz respeito aos eventos e aos periódicos científicos. No entanto, segundo Campello (2003), o evento apresenta uma peculiaridade que o destaca em relação aos demais: o contato imediato, face a face, que se firma entre os participantes. Desse modo, mesmo com as tecnologias digitais, as quais promovem o contato simultâneo entre pesquisadores de diferentes partes do mundo (tal como as videoconferências), os eventos presenciais ainda são intensamente utilizados como formas de comunicação científica.

Os eventos científicos são conceituados como atividades de comunicação dirigida, sistematizada e organizada, cujo objetivo é aproximar públicos de diferentes contextos, haja vista permitir a troca de ideias, experiências e conquistas. Portanto, realizar evento trata-se de uma atividade que promove intensa interação, seja entre promotores, organizadores e participantes, desde que esses personagens comunguem de objetivos similares (UNIPAMPA, 2013).

Nesse aspecto, “[...] a interação oral varia de uma conferência pronunciada diante de uma grande plateia até as conversas triviais durante a pausa para o cafezinho [...]". De um modo geral, o contato entre os participantes representa uma das principais finalidades dos encontros científicos. Assim, em alguns casos, é comum notar que muitos participantes dos eventos, em geral, "[...] alegam que não foram ali para assistir às apresentações programadas, mas para conversar com os colegas [...]" (MEADOWS, 1999, p. 139).

Discorre Campello (2003, p. 56, grifo nosso), que a grande vantagem desse tipo de comunicação é ampliar a comunicação pessoal "[...] na medida em que permite troca de informações de maneira intensa, envolvendo maior número de pessoas". No que se refere à comunicação oral do trabalho no encontro, ela é vantajosa, pois possibilita "[...] que críticas e sugestões sejam feitas na hora, de forma a permitir uma retroalimentação instantânea, podendo envolver vários pontos de vista [...]".

Os eventos científicos acontecem de forma das mais variadas, cabendo à equipe organizadora estabelecer as normativas que sustentarão o evento, de modo a seguir fielmente o objetivo principal proposto. Assim, existem eventos que visam abranger uma área específica do conhecimento ou áreas mais amplas, como também o evento pode propor a reunir pesquisadores de um contexto local quanto um contexto mais global (CAMPELLO, 2003).

A autora supracitada apresenta os diversos tipos de eventos existentes, considerando a abrangência e o propósito desse tipo de comunicação. Assim,

$$
\begin{aligned}
& \text { [... alguns encontros voltam-se } \\
& \text { exclusivamente para a comunicação de } \\
& \text { pesquisas e reúnem uma audiência } \\
& \text { empenhada em discutir avanços de seu campo } \\
& \text { de conhecimento, sendo, normalmente, } \\
& \text { organizados pelas associações científicas. } \\
& \text { Outros congregam participantes voltados para } \\
& \text { a prática profissional e são organizados pelas } \\
& \text { entidades profissionais (CAMPELLO, 2003, } \\
& \text { p. 59). }
\end{aligned}
$$

Com efeito, para Campello (2003), em cada um desses casos, a organização e os trabalhos apresentados têm características distintas. De 
maneira geral, os encontros apresentam uma estrutura semelhante, que pode variar de acordo com o tamanho do evento, caracterizando-se como eventos mais abrangentes, denominados de congressos, como eventos mais específicos e delimitados, com denominações variadas, tais como: simpósios, jornadas, seminário, colóquios, fórum, reunião, dentre outras.

De qualquer forma, independentemente do tipo, do propósito e da abrangência do evento, não resta dúvida de que, seu sucesso dependerá, primordialmente, do estabelecimento de um efetivo planejamento, acompanhado de constante monitoramento e ajustes necessários, a serem realizados à medida que as atividades vão sendo desenvolvidas até a efetiva concretização do evento (UNIPAMPA, 2013).

A priori, a equipe organizadora deve pautar-se em princípios administrativos para consolidação do planejamento estratégico do evento, o qual deverão ser estabelecidos os objetivos do evento, o público-alvo atingido, o delineamento das estratégias, o levantamento dos recursos, implantação das ações, os critérios para avaliação e, por fim, o orçamento previsto (UNIPAMPA, 2013).

Desse modo, a prática de organização de um evento científico não constitui um processo simplista, mas, ao contrário, requer, a princípio, o estabelecimento de uma comissão com profissionais munidos de múltiplas e diversificadas responsabilidades. Destarte, os agentes envolvidos na organização devem conduzir um processo de trabalho colaborativo, determinando tarefas entre as equipes e estabelecendo prazos a serem cumpridos (UFG, s.d.).

Portanto, por meio de um trabalho bem organizado pelas equipes, os participantes do evento, sobretudo os que apresentarão pesquisas, terão suas atividades otimizadas, podendo assumir uma postura adequada e satisfatória a fim de comunicar precisamente as informações oriundas de seus estudos e satisfazendo os desejos dos participantes, de acordo com as normas exigidas para uma efetiva comunicação científica, como nos ensina Muñoz (s. d.). Por conseguinte, evidencia-se que a comunicação científica tornar-se-á mais adequada, permitindo a troca de opiniões entre os participantes do evento, acerca das descobertas e ideias apresentadas.

\section{EBCIM: CONTEXTO, VIVÊNCIA E PROCEDIMENTOS REALIZADOS NA MONITORIA}

Conforme discutido na seção anterior, a prática de organização de um evento científico, seja ele de qualquer modalidade, requer um planejamento bem elaborado, conduzido por atividades diferenciadas, que aconteçam de forma processual, envolvendo diferentes equipes de trabalho.

Observa-se que o sucesso de qualquer evento científico dependerá da forma como o planejamento foi elaborado e as estratégias utilizadas para sustentar as diversas atividades executadas, desde o momento em que se forma a comissão organizadora, até o momento final, em que são disponibilizados aos participantes, os relatórios finais dos resultados alcançados com o evento, relatórios esses que, na maioria das vezes, são disponibilizados aos participantes, por meio de publicações específicas, denominadas de anais.

No caso específico do EBCIM/2016, observa-se sua ampla abrangência (contemplando países de um bloco econômico). Todavia, tal evento abarcou um público específico, representado por diretores, docentes ou sujeitos envolvidos com o ensino prestado nas escolas de Biblioteconomia. De qualquer forma, não resta dúvida de que esse encontro revestiu-se de um caráter interdisciplinar, o que não foge a qualquer outro evento correlato a essa área, como nos ensina Gomes (2006, p. 1), ao proferir que "investigar a produção do conhecimento em biblioteconomia e ciência da informação implica discutir a definição desses campos e, consequentemente, a complexa delimitação de suas interfaces com outros campos do conhecimento [...]".

Nesse contexto, o EBCIM/2016 teve como tema principal "A Biblioteconomia em diálogo com a Arquivologia e a Museologia: desafios e interlocuções em equipamentos culturais", abarcando como principais atividades: reuniões e visitas técnicas, lançamentos de livros, conferências e apresentação de comunicações (artigos científicos), distribuídas por sete eixos temáticos.

Ressalta-se que a comissão organizadora iniciou as atividades um longo período anterior ao evento, sendo composta por professores e servidores da ECI/UFMG, em parceira com docentes de outras escolas de Biblioteconomia do Brasil e de demais países do MERCOSUL, 
por meio de um trabalho colaborativo, sobretudo no que se refere à avaliação dos trabalhos submetidos ao evento.

A fim de garantir uma melhor organização e logística do processo de submissão e avaliação dos trabalhos, optou-se pelo uso do Sistema Online de Acompanhamento de Conferências $(\mathrm{SOAC})^{1}$. Essa plataforma facilitou a inserção dos trabalhos pelos próprios autores, como também o fluxo do manuscrito à medida que era enviado para avaliação, bem como facilitou a comunicação entre autores, editor e avaliadores. Foi registrado, nessa plataforma, um número substancial de trabalhos enviados ao evento, sendo aprovado um total de 47 trabalhos, distribuídos nos seguintes eixos, a saber: Fundamentos da Ciência da Informação, Organização e tratamento da informação, Recursos e serviços de informação, Gestão de unidades de informação, Tecnologias da informação, Pesquisa em Ciência da Informação e, por fim, Práticas e inovação pedagógicas (Quadro 1).

Quadro 1 - Trabalhos aprovados para apresentação no EBECIM/2016 por eixo temático

\begin{tabular}{|c|c|c|}
\hline SEQUÊNCIA & EIXO TEMÁTICO & QUANTIDADE DE TRABALHOS \\
\hline 1 & Fundamentos teóricos & 6 trabalhos \\
\hline 2 & $\begin{array}{c}\text { Organização e tratamento da } \\
\text { informação }\end{array}$ & 3 trabalhos \\
\hline 3 & Recursos e serviços & 3 trabalhos \\
\hline 4 & Gestão de unidades de informação & 3 trabalhos \\
\hline 5 & Tecnologias da informação & 8 trabalhos \\
\hline 6 & Pesquisa em Ciência da informação & 15 trabalhos \\
\hline 7 & Práticas e inovações pedagógicas & 47 trabalhos \\
\hline \multicolumn{2}{|c|}{ TOTAL GERAL DE TRABALHOS }
\end{tabular}

Fonte: elaborado pelo autor (2017) (com base nos Anais do EBCIM/2016).

Em linhas gerais, esses trabalhos foram elaborados por autores dos diversos países que enviaram membros representantes, sendo que a maioria dos trabalhos foi enviada por autores brasileiros (gráfico 1).

Gráfico 1 - Trabalhos aprovados por países participantes do EBCIM/2016

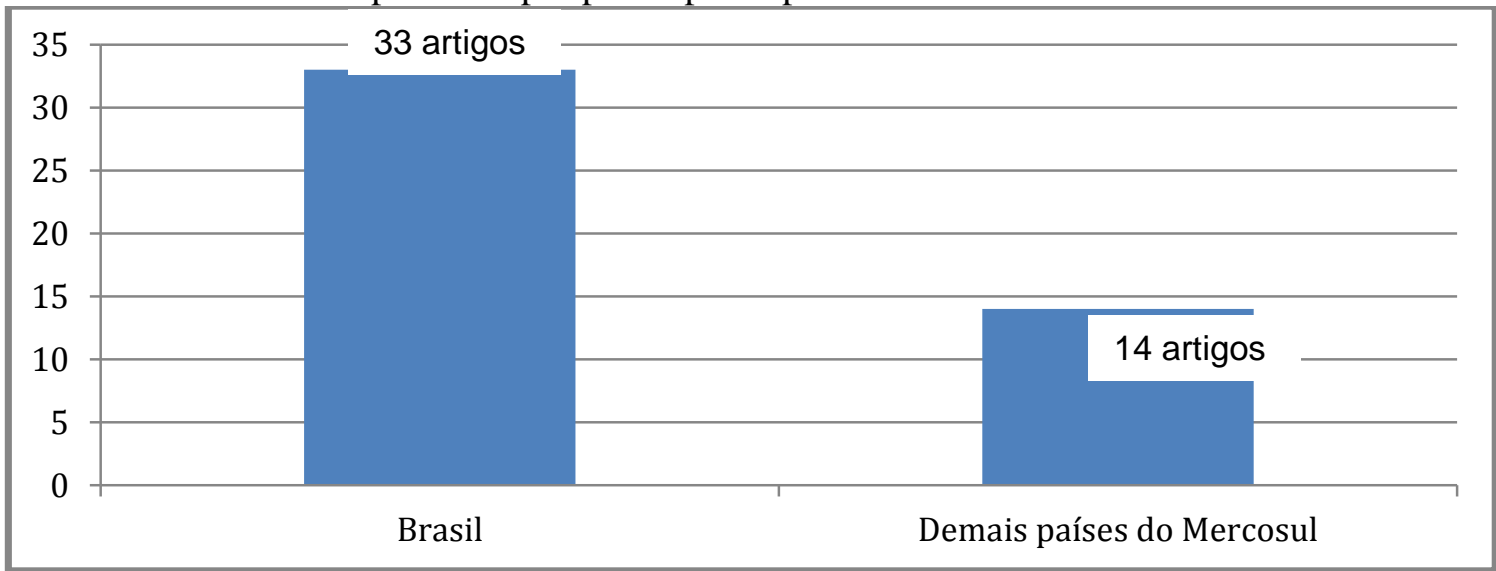

Fonte: elaborado pelo autor (2017) (com base nos Anais do EBCIM/2016).

Importante mencionar que os trabalhos apresentados no referido evento - conforme template disponibilizado no sítio do evento pertenciam à modalidade artigo científico,

\footnotetext{
${ }^{1}$ Refere-se a um processo de customização, feito pelo IBICT, do Open Conference System (OCS). Um software livre para gerenciamento de evento, de cunho preferencialmente acadêmico, que oferece uma variedade de facilidades, com
}

contendo no máximo 15 laudas e foram apresentados na forma de comunicação oral, distribuídos nos sete eixos temáticos.

funcionamento em plataforma web, tornando, assim, uma ferramenta importante na implementação de portais que podem abrigar sites de eventos (IBICT, 2016). 
No que se refere às atividades realizadas no decorrer dos três dias de evento, no primeiro dia (18 de setembro de 2016), manifestou-se a solenidade de abertura, por meio da palestra proferida pelo professor Miguel Angel Rondon Rojas, no Auditório Azul da ECI/UFMG, palestra intitulada "El diálogo entre las disciplinas informativo documentales. Un ejercicio intra, inter y transdisciplinario".

Segundo o discurso de Rojas (2016), é preciso, neste tempo de globalização, estabelecer a aproximação entre as diversas áreas que lidam com a informação, sendo necessário, no contexto da formação curricular, atentar-se para um núcleo central compartilhado, sem contudo, perder os limites demarcatórios de cada campo.

Atrelado a essa necessidade de interação, o referido autor mostrou-se otimista, nestes novos tempos, e destacou o papel de cada profissional, cuja intenção maior deva ser " [...] desarrollar el ser informacional del ser humano, de enriquecerlo, de formarlo culturizándolo y al mismo tiempo enriqueciendo la cultura. Continuemos con esa obra, derecho y deber de los humanistas" (ROJAS, 2016, p. 36).

Em seguida à palestra de Rojas (2016), aconteceu a apresentação dos países participantes, sendo que os membros de cada país proferiu um breve discurso sobre a situação atual das escolas de formação e algumas questões inerentes às titulações e demandas requeridas pelo mercado de trabalho de cada nação. Em linhas gerais, observaramse problemas similares quanto a alguns desafios enfrentados pela Ciência da Informação em todos os países, sobretudo quanto à questão terminológica da área e foi possível identificar similaridades quanto à tentativa de aproximação entre as áreas da informação no âmbito da formação acadêmica.

No segundo dia do evento, dia 19 de setembro de 2016, das 09:00 às 12:00 horas, aconteceu, na sala da congregação da ECI/UFMG, o Encontro de Diretores, em que foram discutidos e compartilhados os problemas enfrentados pelos cursos de formação de cada país. Na ocasião, foram socializadas experiências de fracasso e de sucesso, alcançadas nos diversos contextos nacionais.

No mesmo dia, na parte da manhã, ocorreram duas visitas técnicas: Visita Técnica à Biblioteca Etelvina Lima ECI/UFMG e visita à exposição "D. Quixote - Portinari e Drummond: releituras de Cervantes", essa última ocorrida no Espaço expositivo do Prédio da Reitoria. Ambas as visitas, ocorridas sequencialmente, objetivaram mostrar aos visitantes um pouco dos serviços informacionais oferecidos na UFMG.

Na parte da tarde, qual seja, das 14 às 19:00 horas, despontou-se a apresentação dos trabalhos aprovados, sendo que, para cada eixo temático, foram reservadas salas específicas para apresentação. Os trabalhos foram conduzidos por dois responsáveis em cada sala, sendo um exercendo o papel de moderador e outro de secretário. Além desses agentes, importante considerar que, em cada sala, estavam disponibilizados alunos dos cursos de Graduação e Pós-Graduação da ECI, os quais se manifestaram como grupos de apoio às necessidades demandadas em cada sala, tendo em vista, garantir uma melhor logística das apresentações e comodidade a todos os congressistas presentes nas salas.

Importante frisar que, devido à diferença no número de trabalhos por eixo temático, conforme exposto no quadro 1, os moderadores de cada sala tiveram a liberdade de estabelecer o tempo para cada apresentação, bem como o tempo destinado para perguntas, comentários e demais intervenções. Conforme constava na programação do evento, as comunicações orais poderiam ocorrer em dois dias, ou seja, no dia 19 de setembro (na parte da tarde) e no dia 20 de setembro (na parte da manhã). Todavia, todos os trabalhos puderam ser apresentados no mesmo dia, qual seja, no dia 19 de setembro de 2016.

Ainda no dia 19 de setembro, ocorreu às 17:30 horas, lançamento de livros, no espaço Carro-Biblioteca, sendo apresentado aos congressistas diversos livros brasileiros e internacionais desenvolvidos no últimos anos, relativos a diversos assuntos pertencentes ao campo da Biblioteconomia/Ciência da Informação.

No dia 20 de setembro, de 9:00 as 11:30 horas, aconteceu a reunião dos docentes por área, tendo participação de todos os países presentes, momento esse em que foram discutidos assuntos relativos, sobremaneira, às práticas pedagógicas inseridas no contexto das instituições formativas.

A fim de finalizar o EBCIM/2016, das 13:00 às 15 horas do dia 20 de setembro, ocorreu, no Auditório Azul da ECI, a plenária 
Relatos de Experiência

de fechamento. Na ocasião, cada moderador e secretário dos eixos temáticos relataram os principais assuntos abordados em cada um dos eixos, explanando as observações e conclusões alcançadas, a partir da apresentação das pesquisas.

De acordo com o moderador e secretário do eixo "Fundamentos", grande parte dos trabalhos, a qual abordou pesquisa de âmbito teórico, trouxe abordagens filosóficas, a fim de buscar a identidade da área, bem como os desafios e paradigmas impostos à prática profissional nos últimos anos.

Quanto ao eixo temático "Organização e Tratamento da Informação", a metodologia utilizada nesses trabalhos contemplou estudos de campo, abordando as técnicas de representação, considerando os novos formatos e tipologias de documentos surgidos na atual sociedade.

No que se refere ao eixo "Recursos e Serviços de Informação", também os responsáveis por essa seção explanaram sobre os novos serviços e produtos bibliotecários desenvolvidos com a informatização das unidades de informação. Destacaram-se os desafios inerentes à prática profissional, a qual deve ser aperfeiçoada, de modo a atender esses novos suportes e contextos de informação que estão surgindo.

Em relação ao eixo "Gestão de unidades de informação", os três trabalhos apresentados, segundo os responsáveis pela organização das apresentações, abordaram a intervenção do profissional gestor, o qual deve adquirir um perfil multifacetado, tendo que conhecer técnicas e metodologias administrativas, a fim de desempenhar um efetivo gerenciamento das unidades e serviços de informação. Destaque, também, para a necessidade de ampliação da formação curricular quanto à questão da gestão nos fazeres profissionais.

$\mathrm{O}$ eixo destinado a abordar a "Tecnologia da Informação" teve como assuntos principais a prática da modelagem de dados na construção de novos instrumentos de representação e armazenamento de documentos, como também a gestão de processos no contexto das tecnologias digitais, e a necessidade de ampliação das competências do bibliotecário ao atuar em contextos tecnológicos.

No que tange ao eixo intitulado "Pesquisa em Biblioteconomia e Ciência da Informação", foram destacadas diversas questões, dentre elas: os diversos projetos de pesquisas realizados no âmago das unidades de informação, o papel dos docentes em pesquisas em bibliotecas, museus e arquivos e, por fim, a importância e postura do profissional da informação em realizar pesquisa em seu contexto de trabalho, tendo em vista reconhecer as necessidades atuais e propor ações de melhoria em face dessas novas demandas.

Por fim, quanto ao eixo temático "Práticas e inovação pedagógica", o qual apresentou o maior número de trabalhos, foram abordados assuntos dos mais variados, contemplando, principalmente, a importância da leitura para construção da cidadania, a formação curricular, a formação continuada do professor, dentre outros posicionamentos que devem permear a prática docente quanto profissional. Importante mencionar que, como se tratava de um eixo novo, inserido pela primeira vez no EBCIM, o moderador e secretário propuseram, para um evento futuro, a alocação desse eixo em horário restrito, de modo que os participantes de outros eixos também possam estar presentes nesse eixo. A proposta apresentada foi reformulada pelos congressistas, considerando que, ao invés de horário restrito, o eixo fosse diluído em meio aos demais eixos. Concluiu-se que cada escola decidiria, com seu corpo docente, o que seria melhor, sendo a resposta enviada para a organização do próximo EBCIM, o qual se realizará no Paraguai.

No intuito de sintetizar os principais assuntos discorridos em cada eixo temático, apresenta-se o quadro 2 .

Quadro 2 - Principais assuntos abordados em cada eixo temático do EBCIM/2016

\begin{tabular}{|c|c|c|}
\hline Numeração & Nome do eixo & Principais assuntos discorridos \\
\hline 1 & Fundamentos teóricos & $\begin{array}{c}\text { Integração na Ciência da Informação; contribuições } \\
\text { de Otlet para a Ciência da Informação; Práticas } \\
\text { profissionais; Mediação cultural. }\end{array}$ \\
\hline 2 & $\begin{array}{c}\text { Organização e tratamento da } \\
\text { informação }\end{array}$ & $\begin{array}{c}\text { Representação imagética; Documentos audiovisuais; } \\
\text { Ambientes corporativos de aprendizagem; Biblioteca } \\
\text { Digital de obras raras. }\end{array}$ \\
\hline
\end{tabular}




\begin{tabular}{|c|c|c|}
\hline 3 & Recursos e serviços & $\begin{array}{c}\text { Integração e desafios para Biblioteconomia, } \\
\text { Arquivologia e Museologia; Unidades de informação } \\
\text { como centros de memória; Recursos educativos nas } \\
\text { bibliotecas. }\end{array}$ \\
\hline 4 & $\begin{array}{l}\text { Gestão de unidades de } \\
\text { informação }\end{array}$ & $\begin{array}{l}\text { Planejamento e gestor; Bibliotecas populares; } \\
\text { Bibliotecas em Brasil, Espanha e Moçambique. }\end{array}$ \\
\hline 5 & Tecnologias da informação & $\begin{array}{c}\text { Gestão de processos; Redes sociais em bibliotecas; } \\
\text { Disciplinas instrumentais oferecidas pelo } \\
\text { bibliotecário. }\end{array}$ \\
\hline 6 & $\begin{array}{l}\text { Pesquisa em Ciência da } \\
\text { Informação }\end{array}$ & $\begin{array}{l}\text { Formação profissional na universidade; Atividades } \\
\text { profissionais em unidades de informação; Docência } \\
\text { e investigação; Bibliotecas escolares; Produção em } \\
\text { Biblioteconomia; Pesquisa de usuários; Projetos de } \\
\text { pesquisa em Ciência da Informação; Abordagem } \\
\text { clínica da informação. }\end{array}$ \\
\hline 7 & $\begin{array}{c}\text { Práticas e inovações } \\
\text { pedagógicas }\end{array}$ & $\begin{array}{l}\text { Inovação pedagógica no ensino de Biblioteconomia; } \\
\text { Uso de tecnologias no ensino; Aprendizagem no } \\
\text { ensino de Biblioteconomia; Práticas de biblioteca em } \\
\text { biblioteca e museu; Competência informacional; } \\
\text { Usuários da informação; Linguagem digital; Espaço, } \\
\text { cultura e ação; Educação a Distância; Projeto de } \\
\text { leitura; Prática educativa em museu. }\end{array}$ \\
\hline
\end{tabular}

Fonte: elaborado pelo autor (2017).

Por meio da análise ao quadro 2 , e considerando a especificidade do EBCIM (direcionado a um público mais depurado, qual seja, professores e diretores das escolas de Biblioteconomia), percebe-se a diversidade de temas abordados em todos os eixos temáticos, o que demonstra que o campo da Ciência da Informação e áreas afins vem se consolidando como uma área de pesquisa promissora, em constante crescimento. Assim, é possível aferir que, como em todas as áreas do conhecimento, problemas surgem e as soluções são viabilizadas por meio da prática de pesquisa, fundamentada em métodos científicos, os quais garantem para a consolidação de uma área científica no âmbito da sociedade. Por conseguinte, os eventos científicos surgem para compartilhar essas tendências e viabilizar o desenvolvimento científico.

Após apresentação do relato de cada moderador e secretário acerca dos diversos trabalhos apresentados em cada eixo, a comissão organizadora procedeu-se às palavras finais, discorrendo acerca dos agradecimentos e motivando a participação dos congressistas no próximo ECBIM, que ocorrerá no ano de 2018, na cidade de Assunção, no Paraguai.

Por fim, cumprindo a programação do EBCIM/2016, a partir das 15:30 horas estava prevista a última visita técnica, qual seja, a Visita técnica ao Museu Mineiro e a Biblioteca Estadual Luís de Bessa. No entanto, essa visita não ocorreu (como medida de segurança) devido à possibilidade de intempéries (fortes chuvas) a atingir a cidade de Belo Horizonte nas horas seguintes, conforme estipulado pela previsão do tempo local.

\subsection{RESULTADOS OBSERVADOS: POSSÍVEIS CONTRIBUIÇÕES}

A princípio, pela diversidade nos temas dos trabalhos apresentados, da quantidade de congressistas participantes e da representatividade abrangente que o evento contemplou em nível de MERCOSUL, presume-se que os objetivos principais do evento foram atingidos.

Considerando as palavras iniciais da comissão organizadora, quando da publicação dos Anais Eletrônicos do EBCIM/2016, acerca da trajetória histórica desse evento:

É importante destacar que a realização contínua desses encontros trouxe um amadurecimento das intenções e compromissos estabelecidos em cada um deles. As áreas temáticas têm se mantido estáveis, porém atualizadas, em decorrência da própria evolução das disciplinas envolvidas e também das interlocuções surgidas entre áreas afins, durante todo o período (SOUZA et al., 2016, p. 11, grifo nosso),

Observa-se que esse encontro cumpriu com sua missão, uma vez que provocou ainda mais 
o amadurecimento sobre a necessidade da integração entre as diversas áreas e a troca de conhecimentos e contribuições entre os diversos profissionais existentes no mercado global, de modo que fronteiras possam ser rompidas, em prol de um mercado que comungue dos mesmos desejos e expectativas.

Foi possível perceber que, as diversas atividades realizadas ao longo do evento, tais como conferências, comunicações orais, visitas e reuniões técnicas, dentre outras estão condizentes com o que é exposto na literatura sobre comunicação científica e práticas de organização de ventos. Também constatou-se que o evento proporcionou a troca de experiências entre profissionais de diferentes realidades, instâncias e contextos, fomentando o diálogo presencial entre os participantes, o qual despertou a construção coletiva do conhecimento científico.

Em síntese, é possível identificar diversas atividades realizadas com sucesso ao longo do evento, as quais podem ser consideradas como contribuições a serem adotadas em futuras edições do evento, bem como pode contribuir com habilidades a serem adotadas pelos organizadores quando da prática de organização desse tipo de comunicação científica.

Assim, destacam-se como principais contribuições: a dedicação das equipes de trabalho; o planejamento sustentado por reuniões; a interação entre os organizadores; a receptividade fornecida aos congressistas; os recursos utilizados com tecnologias digitais que muito facilitou o desenvolvimento das atividades; a presença de secretário e moderador em cada eixo temático; a apresentação dos relatórios de cada eixo temático; o auxílio da equipe de monitores formada por alunos de Graduação e PósGraduação; a publicação dos anais logo à concretização do evento; a comunicação firmada entre equipe científica e os autores quanto do processo avaliativo dos trabalhos; a infraestrutura do evento, centralizada em um único edifício, dentre muitos outros pormenores.

A observação realizada ao longo do evento, além de identificar as contribuições, também permitiu aferir algumas sugestões, haja vista garantir a melhoria contínua do evento. Essas sugestões propostas, como também as principais contribuições percebidas estão apresentadas no quadro 3 .

Quadro 3 - Principais contribuições do evento e algumas possíveis sugestões de melhoria

\begin{tabular}{|c|c|}
\hline Principais pontos positivos & Algumas indicações de melhoria \\
\hline $\begin{array}{l}1 \text { - Dedicação; } 2 \text { - Integração; } 3 \text { - } \\
\text { Recursos utilizados; } 4 \text { - planejamento do } \\
\text { evento; } 5 \text { - infraestrutura do evento. }\end{array}$ & $\begin{array}{l}1 \text { - Maior número de reuniões e delineamento na } \\
\text { definição de tarefas; } 2 \text { - inserção do número das salas, } \\
\text { dia e horário específicos da apresentação de cada } \\
\text { trabalho; } 3 \text { - aplicação de uma metodologia avaliativa } \\
\text { do evento, a ser respondida pelos participantes. }\end{array}$ \\
\hline
\end{tabular}

Fonte: elaborado pelo autor (2017).

A partir das diversas ocorrências que permearam as atividades do EBCIM/2016, considera-se que o evento foi benéfico para a área. Um dos pontos sugeridos para próximas edições, diz respeito à aplicação de metodologia, coletando opiniões dos congressistas acerca do evento. Não resta dúvida de que a opinião dos participantes representa um dos melhores métodos para redefinir nossos fazeres, em busca da excelência daquilo que oferecemos a outrem.

A interação do monitor com professores e alunos, na condução das atividades, certamente, contribuiu para o desenvolvimento de habilidades profissionais, sobretudo no que tange à comunicação e trabalho em equipe. Também permitiu ao monitor, adquirir experiências acerca das atividades que são requeridas no planejamento e desenvolvimento de um evento científico, além de despertar a importância do evento e o trabalho integrado firmado entre os docentes e dirigentes das escolas de Biblioteconomia do MERCOSUL.

Tendo em vista que, nos dias atuais, temos que pautar na melhoria contínua de nossos fazeres - como relatam muitos teóricos da Administração - faz-se necessário refletir acerca dos problemas, desafios e dificuldades encontradas, para que essas ocorrências transformem-se em amadurecimento de nossas habilidades quanto ao trabalho em equipe, especificamente, no que se refere às práticas de organização de eventos. Que as vitórias 
alcançadas possam ser replicadas em outros momentos e que as dificuldades sirvam de aprendizado para aprimorar nossas práticas em futuras intervenções.

\section{CONSIDERAÇÕES FINAIS}

Ao findar este relato, conduzido por meio de estudo bibliográfico, documental e observação direta realizada ao longo dos três dias que permearam a ocorrência do EBCIM/2016, foi possível apresentar as principais atividades realizadas no referido evento, como também apontar possíveis contribuições do evento para a área e para o monitor.

Constatou-se que a comunicação científica apresenta-se como um instrumento de divulgação dos trabalhos que estão sendo desenvolvidos em uma área de conhecimento, sendo que, essa comunicação pode se manifestar por meio de diferentes canais, sendo os eventos científicos uma das estratégias mais utilizadas pelos pesquisadores, pois é através desse tipo de apresentação, que se elucidam críticas, apontamentos e sugestões acerca dos temas de pesquisas apresentados.

Os eventos científicos promovem a integração entre profissionais e cientistas de diferentes instâncias e contextos, permitindo, dessa forma, que desafios, conquistas e experiências possam ser compartilhadas, tendo em vista o aprendizado mútuo e contribuindo para a consolidação de uma dada área científica. No caso do EBCIM/2016, notou-se que ele atingiu esses objetivos, principalmente, por ele congregar participantes com interesses similares de pesquisas e viabilizar a integração e padronização quanto às práticas desenvolvidas no processo formativo oferecidas nas escolas de Biblioteconomia dos países integrantes do MERCOSUL.

As diversas atividades realizadas no evento, a riqueza e multiplicidade temáticas presentes nas comunicações orais e os resultados alcançados nas reflexões que foram apresentadas e nas sugestões expostas no final do evento, são fatores suficientes para garantir a viabilidade do evento e a necessidade de sua continuação ao longo das próximas décadas. Quanto às possíveis sugestões de melhoria, é provável que elas sirvam como ponto de reflexão e aprendizado, de modo que nossas práticas sejam sustentadas na garantia de atingirmos a melhoria contínua.

Quanto à atividade de monitoria, considerase que ela agregou valor tanto para o evento quanto para o crescimento profissional do monitor. Ao evento, o grupo de monitores manifestou-se como uma equipe de apoio, contribuindo com o trabalho operacional requerido nas mais diversas atividades realizadas pelas comissões. Ao monitor, o evento serve como uma oportunidade para aquisição de novos conhecimentos relativos à área da Biblioteconomia, como também relacionados ao trabalho gerencial.

A partir da experiência, espera-se que habilidades tenham sido aprimoradas pelos organizadores e auxiliares, principalmente os monitores, de modo que novos eventos possam ser gerenciados de forma colaborativa, com vistas a garantir a melhoria contínua das práticas de organização de eventos. Além disso, que se desperte a necessidade em se preservar e ampliar o número de eventos biblioteconômicos, sobretudo os direcionados aos docentes, no intuito de viabilizar continuamente, o fortalecimento da formação profissional.

\title{
MEETING OF DIRECTORS AND TEACHERS OF THE MERCOSUL LIBRARY SCHOOLS: A MONITORING REPORT
}

\begin{abstract}
Scientific events are considered as important means of scientific communication, used in the most different areas of knowledge. In the area of Librarianship, one of the most important scientific events directed to professional formation is the Meeting of the Directors and Teachers of the Librarianship Schools of Mercosur. Although it is an event of international scope and of great contribution to the Information Science, the objectives and success of the event will only be achieved with the integration of several work teams, mainly students and professionals who are in charge of the monitoring
\end{abstract}


activities. Therefore, this text constitutes an experience report, based on monitoring carried out in the XI edition of the Meeting of Directors and X edition of the Meeting of Teachers. Objective, based on the activities carried out throughout the event, to present the possible contributions resulting from the monitoring. For this, the text presents discussions about practices of organization of events elucidated in the literature; describes the definition and characteristics of the main types of scientific events, according to area theorists; synthesizes the didactic proposals present in the presented articles; and, finally, it discusses the main contributions of the event to the area and to the learning of the monitor. It uses descriptive research, with bibliographic and documentary research procedures, besides the participant observation. The results indicated that the monitoring activity added value for both the event and the professional growth of the monitor, serving as an opportunity to acquire new knowledge related to the area of Librarianship, as well as related to managerial work.

Keywords: Scientific events. Practices of organization of events. Librarianship Schools of Mercosul. Professional qualification.

\section{REFERÊNCIAS}

BUENO, Wilson Costa. Comunicação científica e divulgação científica: aproximações e rupturas conceituais. Informação e Informação, Londrina, v. 15, n. especial, p. 1-12, 2010. Disponível em: $<$ http://www.uel.br/revistas/uel/index.php/inf ormacao/article/view/6585>. Acesso em: 3 out. 2016.

CAMPELLO, Bernadete Santos. Encontros científicos. In: CAMPELLO, Bernadete Santos; CENDÓN, Beatriz Valadares; KREMER, Jeannette Marguerite (Org.). Fontes de informação para pesquisadores e profissionais. Belo Horizonte: Editora UFMG, 2003. p. 55-71.

GOMES, Maria Yêda Falcão. Tendências atuais da produção científica em Biblioteconomia e Ciência da Informação no Brasil. DataGramaZero: Revista de Ciência da Informação, v. 7, n. 3, jun. 2006.

Disponível em:

<http://www.repositorio.ufba.br/ri/handle/ri/2 393>. Acesso em: 3 out. 2016.

\section{IBICT. Sistema eletrônico de}

Administração de Conferências. 2016.

Disponível em:

$<$ http://www.ibict.br/pesquisa-

desenvolvimento-tecnologico-e-

inovacao/sistema-eletronico-de-adminstracaode-conferencias\%28soac\%29>. Acesso em: 3 out. 2016.
MEADOWS, Arthur Jack. A comunicação científica. Brasília, DF: Briquet de Lemos, 1999.

MEDEIROS, João Bosco. Redação

científica: a prática de fichamentos, resumos, resenhas. 11. ed. São Paulo: Atlas, 2009.

MUELELR, Suzana Pinheiro Machado. A ciência, o sistema de comunicação científica e a literatura científica. In: CAMPELLO, Bernadete Santos; CENDÓN, Beatriz Valadares; KREMER, Jeannette Marguerite (Org.). Fontes de informação para pesquisadores e profissionais. Belo Horizonte: Editora UFMG, 2003. p. 21-34.

MUÑOZ, Rilva. Apresentação oral de trabalhos científicos. [s.d.]. Disponível em: $<$ http://pt.slideshare.net/rilvalopes/apresentao -oral-de-trabalhos-cientficos-profa-rilvamuoz>. Acesso em: 3 out. 2016.

ROJAS, Miguel Ángel Rendón. El diálogo entre la archivística, la bibliotecología, la ciencia de la información y la museología. Un ejercicio intra, inter, multi y transdisciplinario. In: ENCONTRO DE DIRETORES, 11 e ENCONTRO DE DOCENTES DE ESCOLAS DE BIBLIOTECONOMIA E CIÊNCIA DA INFORMAÇÃO DO MERCOSUL, 10. Anais eletrônicos... Belo Horizonte: UFMG, 2016. Disponível em:

<http://mercosur2016.eci.ufmg.br/wp- 
content/uploads/2016/10/AnaisMercosur5.pdf >. Acesso em: 3 set. 2016.

SENARC. Técnicas de apresentação e comunicação e formação de instrutores de capacitação. Brasília: SENARC, 2009.

Disponível em:

<https://www.google.com.br/>. Acesso em: 3 out. 2016.

SOUZA, Terezinha de Fátima et al. Apresentação. In: ENCONTRO DE DIRETORES, 11 e ENCONTRO DE DOCENTES DE ESCOLAS DE BIBLIOTECONOMIA E CIÊNCIA DA INFORMAÇÃO DO MERCOSUL, 10. Anais eletrônicos... Belo Horizonte: UFMG, 2016. Disponível em: <http://mercosur2016.eci.ufmg.br/wpcontent/uploads/2016/10/AnaisMercosur5.pdf >. Acesso em: 3 set. 2016.

UFG. Manual de planejamento de eventos. [s.d.]. Disponível em:

<https://www.ascom.ufg.br/up/84/o/manual_p lanejamento_de_eventos_completo.pdf_green >. Acesso em: 3 out. 2016.

UNIPAMPA. Guia para organização de eventos. Pampa: Unipampa; Assessoria de Comunicação Social, 2013. Disponível em: $<$ http://cursos.unipampa.edu.br/cursos/relacoe spublicas/files/2012/01/Guia-paraOrganiza\%C3\%A7\%C3\%A3o-de-EventosUnipampa.pdf.>. Acesso em: 3 out. 2016. 